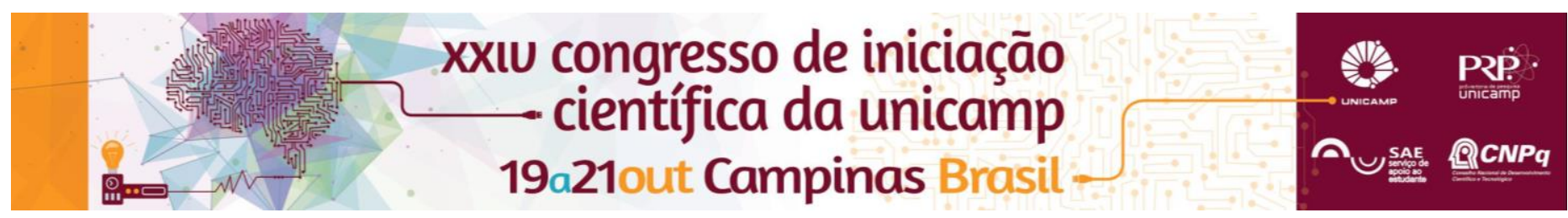

\title{
Método de Simulação para o Dimensionamento de Redes de Dados com Foco em Dados Stream.
}

\section{Edson Luiz Ursini, Fernando Henrique Pereira Pinho*.}

\section{Resumo}

Este trabalho consiste no levantamento de informações sobre a rede do campus e da elaboração de modelos de simulação por eventos discretos no software de simulação ARENA que foram válidados em projeto de pesquisa prévio em comparação com modelos analíticos. Seu foco são os dados do tipo stream e a partir dos dados encontrados permitir o estudo de dimensionamento da rede do campus em casos de ampliação como também o uso dos dados para trabalhos futuros em planejamento e dimensionamento de redes de comunicação.

\section{Palavras-chave:}

Simulação por eventos discretos, Dimensionamento de rede, Tráfego Stream.$$
\text { Introdução }
$$

Visando estudos de qualidade de serviço e dimensionamento de redes de dados este trabalho tem como objetivos analisar a rede do campus da FTUNICAMP por meio de modelos de simulação por eventos discretos com foco em dados do tipo stream (sensíveis a atraso) em comparação com os elásticos (sensíveis a perda). Com os dados extraídos das simulações de tráfego de rede em relação a dados stream será possível no futuro realizar novos trabalhos com esses dados e/ou a utilização dos mesmos para um dimensionamento e/ou ampliação real da estrutura de rede do campus em relação a serviços que hoje não são contemplados em sua infraestrutura, como por exemplo os serviços de voz sobre IP(VoIP) e vídeo conferência.
\end{abstract}

\section{Resultados e Discussão}

Através da elaboração de modelos como o exemplificado na Figura 1 e que foram válidados em projetos de pesquisa prévios em comparação a modelos analíticos que podem ser utilizados tanto para o tráfego elástico quanto para o stream e que são adequados/calibrados para chegadas Poissonianas foram obtidas informações como número de pacotes perdidos e número de pacotes entregues para os serviços de VolP e Video Conferência que são serviços que utilizam dados do tipo stream.

As simulações foram feitas a partir de dados de utilização real da rede do campus (composto por dados elásticos, ou seja, sensíveis a perda de pacotes) com exceção dos novos dados para serviço do tipo stream, porque esses serviços ainda não foram contemplados pela infraestrutura do campus. Nosso objetivo é justamente o de ver qual o comportamento das simulações com diferentes valores para o caso um novo dimensionamento incluindo dados stream. Em trabalhos futuros podem ser simulados tráfegos com outras características de chegadas, como por exemplo, Weibull ou Lognormal.
Figura 1. Exemplo de modelo composto no Software ARENA para simulações por eventos discretos.

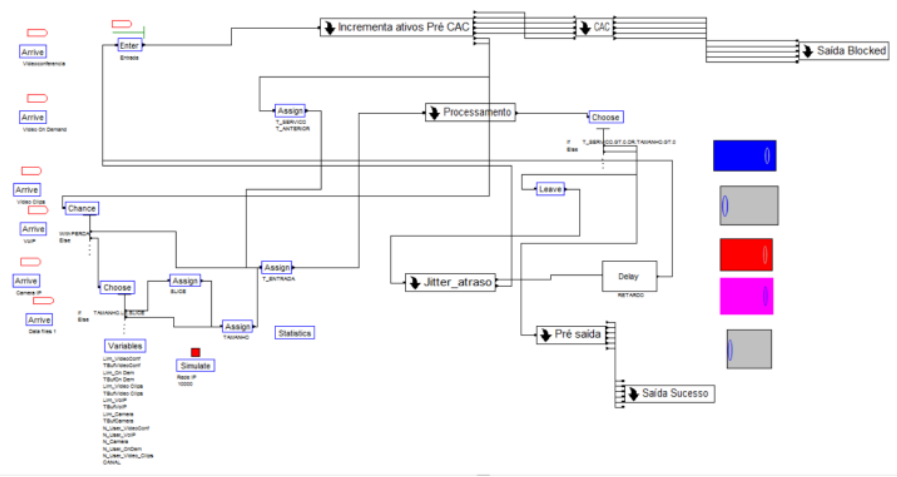

\section{Conclusões}

As simulações realizadas observam aspectos relacionados a um modelo específico e com foco em dois tipos de serviço: VoIP e Videoconferência. Os modelos podem ser melhorados em trabalhos futuros a partir do levantamento de novas informações reais sobre determinado tráfego a ser estudado e/ou por meio de novos modelos de simulação que contemplem outros aspectos como os CODECs (codificadoresdecodificadores) utilizados e características de Policiamento de tráfego.

\section{Agradecimentos}

Agradecimentos ao orientador Edson Luiz Ursini e a instituição de fomento: PIBIT/FUNTEL

\footnotetext{
PProjeto de Pesquisa PIBITI 2013 "Metodologia de Modelos Analíticos e de Simulação para o Dimensionamento de Redes de Dados", Michael Soares da Silva Fonseca.

${ }^{2}$ A. Riedl, T. Bauschert and A. Probst, Dimensioning of IP access networks with elastic traffic,NETWORKS 2000, Proceedings, Toronto, 2000.

${ }^{3}$ Trabalho de Graduação Interdisciplinar CESET-2006(Autores:Diogo Faria Bernardi eTito RicardoBianchin Oliveira).

${ }^{4}$ do PRADO, Darci Santos. Utilizando o ARENA em Simulação. Série Pesquisa operacional, volume 3, editora de Desenvolvimento Gerencial, 1999.
} 